\title{
Impacto Econômico do COVID-19 sobre a Estrutura Produtiva do Estado do Rio de Janeiro
}

\author{
Joilson de Assis Cabral* \\ Everlam Elias Montibeler ${ }^{\dagger}$ \\ Maria Viviana de Freitas Cabral \\ Thierry Molnar Prates ${ }^{\S}$ \\ Daniel Rodrigues Cordeiro ${ }^{\mathbb{I}}$
}

\begin{abstract}
Resumo
O objetivo deste trabalho consistiu em estimar os efeitos do Covid-19 sobre a estrutura produtiva do estado do Rio de Janeiro. Para tanto, foi utilizado o método de insumo-produto considerando três possíveis cenários de acordo com a eficácia do isolamento social para conter o contágio. Os resultados revelaram que a redução do PIB fluminense será de 4,16\% a $5,02 \%$, sendo comércio e serviços os setores mais impactados. Para amenizar estes resultados negativos sobre a economia, a indústria extrativa fluminense terá um crescimento estimado de 1,15\% a 2,25\% em 2020. Torna-se urgente uma política fiscal expansionista liderada pelo governo federal.
\end{abstract}

Palavras-chave: Covid-19; Estrutura produtiva fluminense; Impactos econômicos; InsumoProduto.

\begin{abstract}
The purpose of this article was to estimate the effects of Covid-19 on the productive structure of Rio de Janeiro's state. Thus, the input-output method was used considering three possible scenarios according to the effectiveness of social isolation to contain contagion. The results
\end{abstract}

\footnotetext{
*Professor do Departamento de Ciências Econômicas e Docente permanente dos Programas de Pós-graduação em Economia Regional e Desenvolvimento e do Gestão e Estratégia todos da Universidade Federal Rural do Rio de Janeiro. E-mail: cabraljoilson@gmail.com. ORCID: https://orcid.org/0000-0002-6304-0195

†'Docente permanente dos Programas de Pós-graduação em Economia Regional da Universidade Federal Rural do Rio de Janeiro. E-mail: everlamelias@ gmail.com. ORCID: https://orcid.org/0000-0001-8899-8669

†Professora do Departamento de Ciências Econômicas e Docente Permanente do Programa de Pós-graduação em Economia Regional e Desenvolvimento ambos da Universidade Federal Rural do Rio de Janeiro. E-mail: mvivianafreitas@gmail.com. ORCID: https://orcid.org/0000-0003-4825-7713

${ }^{\S}$ Professor do Departamento de Ciências Econômicas e Docente permanente do Programa de Pós-graduação em Economia Regional e Desenvolvimento. E-mail: thierry@ ufrrj.br. ORCID: https://orcid.org/0000-00034070-1605

"Professor da Universidade Iguaçu - UNIG. E-mail: danielrodriguesco@gmail.com. ORCID: https://orcid.org/0000-0002-3127-7083
} 
revealed the reduction of the Rio de Janeiro state GDP will be from $4.16 \%$ to $5.02 \%$, with commerce and services being the sectors most impacted. To mitigate these negative results, the extractive industry in Rio de Janeiro will have an estimated growth of $1.15 \%$ to $2.25 \%$ in 2020. An expansionist fiscal policy led by the federal government is urgently needed.

Keywords: Covid-19; Rio de Janeiro state productive structure; Economic impacts; InputOutput.

JEL: R11; R15.

\section{Introdução}

Um surto de pneumonia de origem desconhecida surgiu no final de dezembro de 2019, na cidade de Wuhan, província de Hubei na China (SOHRABI et al., 2020; LU et al., 2020; CHAN, 2020). Em 30 de janeiro de 2020, a Organização Mundial da Saúde (OMS) declarou uma emergência de saúde pública de interesse internacional sobre o surto global do que foi denominado "novo coronavírus 2019 (2019-nCoV)" (OMS, 2020a), também conhecido como "Coronavirus Disease 2019 (Covid-19)" (BAE, 2020; OMS, 2020c). Por fim, um grupo de virologistas chineses sugeriu renomear o SARS-CoV-2 para "human coronavirus 2019 (HCoV-19)", uma vez que as pessoas poderiam desenvolver pânico ao imaginar a recorrência da SARS que ocorreu em 2002, também com origem na China (JIANG et al., 2020).

Diante da inexistência de uma vacina contra a doença e devido à disseminação global do Covid-19, a OMS classificou o coronavírus como pandemia em 11 de março de 2020. Como forma de reduzir o contágio, os mesmos princípios básicos para reduzir o risco geral de transmissão de infecções respiratórias agudas devem ser seguidos, segundo a OMS (2020b), autoridades e especialistas da área de saúde. Entre as medidas que buscam reduzir o índice de contágio podem ser citados: i) o distanciamento social; ii) lavagem frequente das mãos; iii) aprimoramento das práticas padrão de prevenção e controle de infecções em hospitais, especialmente em serviços de emergência.

Segundo Sohrabi et al. (2020) e OMS (2020b), estas medidas também visam combater a desinformação e minimizar o impacto social e econômico em escala global (SOHRABI et al., 2020; OMS, 2020b). Apesar de mais eficazes para conter a disseminação em larga escala do Covid-19, as medidas de isolamento social e, em última instância, lockdown, causam consequências socioeconômicas de curto, médio e longo prazo, devido à redução de demanda e interrupção de processos produtivos.

No Brasil, o primeiro caso do Covid-19 registrado oficialmente ocorreu em fevereiro de 2020 no estado de São Paulo. A partir de então, a doença tem penetrado rapidamente todos os estados brasileiros. O Rio de Janeiro, segundo estado mais impactado pela pandemia até Julho (MINISTÉRIO DA SAÚDE, 2020) publicou o decreto estadual no 47.027 em 13

Econômica-Niterói, v. 22, n. 1, p. 77-93. Junho, 2020 
de abril de 2020 (ERJ, 2020), que dispõe sobre as medidas de enfrentamento da propagação decorrente do novo coronavírus. Este decreto estabeleceu fechamento dos setores não essenciais além de impor uma série de restrições à circulação de pessoas. Tais restrições levaram à redução da demanda de todos os setores da economia, cujo maior impacto recaiu sobre os setores não essenciais.

Neste contexto, o objetivo deste trabalho consiste em estimar os impactos das medidas de isolamento social adotadas pelo estado do Rio de Janeiro sobre a estrutura produtiva fluminense. Por meio do método de insumo-produto, três possíveis cenários foram traçados: 1) as medidas de isolamento social terminariam no mês de junho (3 meses); 2) as medidas de isolamento social terminariam no mês de agosto (6 meses); 3) as medidas de isolamento social terminariam no mês de outubro de 2020 (8 meses).

O método de insumo-produto é um importante instrumento para analisar a estrutura produtiva de uma determinada região, sendo capaz de estimar os efeitos exógenos provocados pela crise sanitária na demanda final sobre os setores produtivos da economia fluminense. Como base de dados, será utilizada a matriz de insumo-produto regional para o Estado do Rio de Janeiro (MIP-RJ) desagregada em dezesseis setores produtivos para o ano de 2015 construída por Cabral e Oliveira (2020).

Além dessa seção introdutória, o presente trabalho está estruturado como segue. A segunda seção realiza uma breve revisão dos trabalhos que buscaram estimar os efeitos do Covid-19 na economia. A terceira seção aborda a metodologia implementada, bem como a descrição dos dados utilizados. Já na quarta seção, são discutidos os resultados e, por fim, as considerações finais e as implicações políticas do estudo são empreendidas na quinta seção.

\section{Revisão da Literatura}

Por se tratar de um assunto inédito e urgente, a busca pela compreensão dos efeitos da pandemia sobre a economia provocou intensa mobilização de pesquisadores. Diversos estudos foram lançados recentemente com o objetivo de mensurar os impactos do Covid-19 na economia brasileira. De forma geral, os principais aspectos desses efeitos vão desde a redução da produção industrial até perdas em capital humano devido às mortes e absenteísmo causados pela doença.

Em virtude de o vírus ser desconhecido e a pandemia possuir uma dinâmica própria, o fenômeno e seus reflexos sobre a sociedade são complexos. Os pesquisadores, geralmente, utilizam parâmetros condicionados ao grau de distanciamento social que as autoridades impõem e estabelecem cenários sobre esses efeitos na economia. O comportamento das autoridades e das pessoas frente à realidade e estágio da pandemia implica em maiores ou menores impactos socioeconômicos.

Um dos primeiros trabalhos que mensurou os impactos do Covid-19 na economia foi desenvolvido por Duan et al. (2020) para a China. Utilizando a metodologia de insumoproduto, os autores consideraram três cenários: pior, médio e conservador para estimar 
os efeitos da pandemia. Para tanto, foi considerada a ação efetiva do estado chinês para que a crise não se estendesse no longo prazo. Os resultados revelaram que o Covid-19 impactará a economia como um todo, sendo setores como os de transporte, turismo, varejo e entretenimento os que registrarão maior queda (até 18

No contexto nacional, os estudos lançados recentemente analisam os impactos do Covid19 sobre os setores da economia brasileira ou recortes territoriais estaduais, por meio da metodologia do Equilíbrio Geral Computável (EGC) ou de insumo-produto. Sem aplicação empírica, Haddad et al. (2020) propuseram uma metodologia para mensurar e avaliar os impactos das medidas de lockdown para a economia brasileira e/ou regiões utilizando a abordagem de insumo-produto. A proposta metodológica divide os trabalhadores em grupos de acordo com o grau de impacto ao qual estarão sujeitos devido às medidas de distanciamento social (total ou parcialmente), além de simular os efeitos das políticas governamentais que tem o objetivo de minimizar os impactos socioeconômicos decorrentes da crise sanitária. A metodologia proposta por Haddad et al. (2020) baseia-se em uma adaptação do método de extração hipotética de Dietzenbacher et al. (1993), uma vez que os autores propõem reduzir parcialmente a estrutura produtiva, por meio da redução do consumo intermediário dos setores impactados pelas medidas de distanciamento social, atribuindo percentuais de redução diante dos cenários apresentados. Esse conhecimento é fundamental para a gestão de políticas públicas que minimizem os efeitos do lockdown no nível de atividade econômica, atuando com maior peso sobre atividades que recebam maior impacto.

Dweck et al. (2020) simularam os possíveis impactos do Covid-19 decorrentes das variações nos componentes da demanda final (Consumo das Famílias, Exportações, FBCF das empresas e famílias e gastos do governo) da economia brasileira. Para tanto, foi utilizada a metodologia de insumo-produto com uma matriz desagregada para 127 produtos e 67 setores em três cenários possíveis (otimista, referência e pessimista). Os cenários construídos decorrem da possibilidade de uma quarentena eficiente, assim como da capacidade de ação do governo para reduzir o impacto negativo na renda das famílias. A velocidade de retomada econômica mundial é também fator determinante para o crescimento da demanda. Para os autores, quanto maior a eficiência dessas duas medidas internas e do impacto da demanda externa, mais próxima estará à economia de um cenário otimista de recuperação. Os resultados do estudo evidenciaram que as medidas de isolamento social implicarão em redução de $-3,1 \%$ a $-11,0 \%$ sobre o PIB brasileiro. Com relação ao emprego, o número de ocupações pode oscilar entre $-4,4 \%$ até $-14 \%$ num cenário pessimista, atingindo principalmente trabalhadores do comércio e outras atividades de serviços. Cabe à indústria de transformação, por sua vez, a responsabilidade pela queda de $69,8 \%$ na arrecadação total.

Porsse et al. (2020) também mensuraram os impactos do Covid-19 para a economia brasileira por meio do modelo inter-regional dinâmico de EGC, considerando dois cenários: 1) paralisação econômica por dois meses decorrente do isolamento social e o choque na oferta de trabalho ocasionada pela morbidade e mortalidade; 2) além dos quesitos de 1), foi adicionada a ação governamental com estímulos fiscais a empresas e cidadãos. Os resultados apontaram para uma redução do PIB brasileiro de $1,87 \%$ no primeiro cenário. Caso o go-

Econômica-Niterói, v. 22, n. 1, p. 77-93. Junho, 2020 
verno adote medidas de auxílios emergenciais, o impacto sobre a economia seria amenizado em 35,2\%, de tal modo que a retração decorrente do Covid-19 seria de 1,21\% em 2020.

Analisar os impactos econômicos do Covid-19 na economia nacional é importante. Todavia, por se tratar de um agregado de economias regionais com especificidades locais diversas, torna-se fundamental analisar os efeitos econômicos do Covid-19 a nível estadual. Além da diversidade e especificidade da estrutura produtiva existente entre as regiões brasileiras, cabe observar também que os estados brasileiros não foram impactados pela pandemia de forma homogênea nem simultânea. Com isso, pesquisas com vistas a mensurar os impactos da pandemia sobre as economias estaduais são ferramentas imprescindíveis para as autoridades locais no enfrentamento da crise e no planejamento de medidas econômicas de curto, médio e longo prazos para o planejamento e retomada econômica pós-pandemia.

Nesse sentido, os estudos de Ribeiro et al. (2020) e Santos et al. (2020) analisaram os impactos econômicos do Covid-19 para os estados de Sergipe e Bahia, respectivamente. A metodologia de extração hipotética parcial proposta por Haddad et al. (2020) foi utilizada em ambos os trabalhos. Os resultados para diversas extrações baseadas em quatro diferentes cenários apresentam reduções dos PIBs estaduais que vão de $-5,42 \%$ a -10,63\%, em Sergipe e queda de $-6,04 \%$ a $-11,84 \%$ no estado da Bahia, sujeitos ainda ao grau discricionário de intervenção governamental para atenuar esses problemas com políticas compensatórias (RIBEIRO et al., 2020; SANTOS et al., 2020).

Para o estado de Minas Gerais, Domingues et al. (2020) utilizou o modelo de Equilíbrio Geral Computável para medir os impactos em diferentes cenários de isolamento social. A análise se restringe a medir o efeito apenas da disponibilidade de uso da mão de obra, isto é, sobre os afastamentos do trabalho por morbidade e os óbitos, sem a pretensão de mensurar o impacto total na economia. De modo a alcançar o objetivo proposto, os autores articularam dois modelos, um epidemiológico e outro econômico, facilitando assim a percepção dos cenários da pandemia com os efeitos na economia ao longo do período de isolamento social. Os três cenários analisados foram: "distanciamento estendido", "isolamento parcial" e "sem distanciamento". Os resultados mostraram que o PIB de Minas Gerais reduziria 1\%, ou R \$19 bilhões, caso o estado optasse por um distanciamento estendido. Caso a opção do estado mineiro fosse por um cenário sem distanciamento, a perda seria de $\mathrm{R} \$ 69$ bilhões, ou $4 \%$ do PIB estadual. Portanto, tais resultados comprovam a falsa dicotomia entre saúde e economia quando se trata de enfrentar a pandemia. O distanciamento social estendido resultaria em perdas menores à força de trabalho (DOMINGUES et al., 2020).

Sabendo que a economia do Rio de Janeiro é a segunda maior do Brasil, o presente trabalho contribui para a literatura de economia regional ao estimar os impactos sobre a estrutura produtiva fluminense. A análise dos impactos do Covid-19 sobre a economia do Rio de Janeiro pode ser útil para antecipar e planejar medidas econômicas do governo estadual para a retomada econômica no pós-pandemia. 


\section{Metodologia e Base de Dados}

Esta seção visa descrever a metodologia que será utilizada com o intuito de alcançar o objetivo proposto anteriormente e gerar informações que facilitem a interpretação dos resultados. Também cabe a essa seção descreve os dados utilizados neste trabalho.

\subsection{Modelo de Insumo-Produto}

Este trabalho utilizará o modelo de insumo-produto como metodologia por meio de simulações de redução da demanda final para a economia do estado do Rio de Janeiro em três cenários diferentes.

Segundo Leontief (1986, p. 5), “a análise de insumo-produto é uma extensão prática da teoria clássica de interdependência geral, que vê a economia inteira de uma região, de um país ou, inclusive do mundo, como um só sistema e se propõe interpretar todas as suas funções em termos das propriedades específicas mensuráveis de sua estrutura". A estrutura analítica de insumo-produto desenvolvida por Leontief (1941) fornece a descrição completa das interdependências ou interações (sobre as óticas de compra e venda) dos setores produtivos em determinado tempo e localidade (nação, região, estado) (MILLER e BLAIR, 2009).

O modelo de insumo-produto parte da hipótese de equilíbrio na qual a quantidade demandada é idêntica à quantidade produzida de bens e serviços, tendo como premissas: (i) coeficiente tecnológico constante, (ii) retornos constantes de escala, (iii) demanda final definida exogenamente e (iv) preços rígidos. O modelo de insumo-produto de Leontief (1941) é uma adaptação da teoria neoclássica de equilíbrio geral para o estudo empírico das interrelações entre os vários setores de uma economia.

A representação básica da tabela de insumo-produto tem o objetivo de mostrar a relação de compra e venda setorial ao longo do processo produtivo e suas inter-relações com a demanda final. Os fluxos inter-setoriais de bens e serviços de uma economia com uma região e $\mathrm{n}$ setores, determinados por fatores tecnológicos e econômicos, podem ser representados da seguinte forma (MILLER e BLAIR, 2009):

$$
\begin{array}{cccccc}
z_{11} & +z_{12} & +\ldots & +z_{116} & +y_{1} & =X_{1} \\
\vdots & \vdots & & \vdots & \vdots & \vdots \\
z_{161} & +z_{162} & +\ldots & +z_{1616} & +y_{16} & =X_{16}
\end{array}
$$

Onde $Z_{i j}$ representa o valor do fluxo monetário observado do setor $i$ para o setor $j$. Nas linhas dessa sub-matriz, os valores monetários denotam as vendas dos 16 setores, isto é, os destinos dos produtos de cada atividade. As colunas, por sua vez, expressam a parcela que compõe a produção das 16 atividades pela ótica de seus custos, ou seja, as compras de insumos de cada setor necessárias para a produção. O vetor $y_{i}$ representa a demanda final dos 16 setores do Rio de Janeiro. A demanda final é composta pela formação bruta de 
capital fixo - I, exportações - E, consumo do governo - G e consumo das famílias - C. E finalmente, $X_{i}$ denota o valor bruto da produção dos 16 setores do Rio de Janeiro.

Reescrevendo a equação (1) em notação matricial, tem-se:

$$
Z+Y=X
$$

Onde: $\mathrm{Z}$ é uma matriz 16x16, que representa os coeficientes de relações intra e intersetoriais (consumo intermediário), Y é um vetor 16x4 onde é denotada a demanda final da economia, por fim, $\mathrm{X}$ é um vetor 16x1, onde os elementos representam o Valor Bruto da Produção dos setores.

A equação (2) pode ser reescrita em termos de uma matriz de coeficientes técnicos (A), conhecida como matriz de coeficientes diretos, uma vez que A pode ser definida como:

$$
A=Z(\hat{X})^{-1}
$$

Em que $\hat{X}$ é a matriz diagonal de $\mathrm{X}$ (valor bruto da produção) e cada elemento da matriz de coeficientes diretos (A) é definido da seguinte forma:

$$
a_{i j}=z_{i j} / x_{j}
$$

Onde $a_{i j}$ é chamado de razão de insumo-produto, coeficiente técnico ou coeficiente de requerimento direto. Cada elemento $a_{i j}$ fornece informações sobre os efeitos diretos de uma variação exógena na demanda final. Por meio da equação (4), é possível verificar que a razão de coeficientes técnicos representa a relação fixa entre os insumos utilizados na produção e o total produzido por cada setor.

A matriz A em um modelo de insumo-produto pode ser ilustrada como segue:

$$
A=\left[\begin{array}{ccc}
a_{11} & \ldots & a_{116} \\
\vdots & \ddots & \vdots \\
a_{161} & \ldots & a_{1616}
\end{array}\right]
$$

Na diagonal principal da matriz A são explicitados os coeficientes técnicos intra-setoriais, enquanto que a diagonal secundária denota os coeficientes diretos inter-setoriais. Substituindo a equação (3) na equação (2), tem-se:

$$
A X+Y=X
$$

Colocando a equação anterior em função de Y (demanda final), chega-se a:

$$
X=(X-A)^{-1} Y
$$

Em que I é uma matriz identidade (16x16), $(I-A)^{-1}=B$ é uma matriz (16x16) conhecida como matriz inversa de Leontief ou matriz de coeficientes diretos e indiretos. 
No modelo, com o vetor de demanda final setorial conhecido e fixo, pode-se determinar o vetor de produção total setorial por meio da equação matricial chave do modelo de insumoproduto regional como segue:

$$
X=B Y
$$

Esta equação-chave do modelo de insumo-produto básico de Leontief é classificada como de tecnologia baseada na indústria e com enfoque setor x setor. Por meio da Equação (8), pode-se mensurar os impactos diretos e indiretos no VBP oriundos de choques exógenos da demanda final. Como as medidas de distanciamento social impactam a demanda pelos produtos e serviços dos diversos setores da economia, a metodologia possui aderência para alcançar o objetivo proposto. Entendimento similar dos impactos da pandemia na demanda final foi encontrada em Dweck et al. (2020).

Desta forma, os impactos econômicos setoriais das medidas necessárias de enfrentamento do novo coronavírus sobre a economia fluminense podem ser calculados como segue:

$$
\tilde{X}=B \tilde{Y}
$$

Onde: $\tilde{Y}$ é a matriz de demanda final em que são considerados os impactos setoriais do decreto 47.027 de 13 de abril de 2020 do governo do estado do Rio de Janeiro (ERJ, 2020) para os três cenários propostos. De modo a estimar os impactos econômicos propriamente ditos, serão computadas as variações percentuais do VBP setorial da seguinte forma:

$$
\Delta X_{i} \%=\frac{\tilde{X}_{i}}{X_{i}} * 100
$$

Por meio da Equação 10, é possível mensurar o nível percentual de perturbação da pandemia sobre a VBP do estado do Rio de Janeiro.

\subsection{Base de Dados}

De modo a implementar o modelo de insumo-produto, este trabalho utiliza uma matriz de insumo-produto regional para o estado do Rio de Janeiro (MIP-RJ). Com tecnologia setor x setor distribuída em 16 setores produtivos para o ano de 2015, a MIP-RJ foi construída por Cabral e Oliveira (2020).

Os três cenários propostos neste estudo seguem as recomendações dos epidemiologistas de que, caso a taxa de isolamento social para o enfrentamento do Covid-19 atingisse 70\%, a economia poderia ser reaberta em 3 meses (cenário 1). Caso essa taxa não fosse atendida, e a taxa de isolamento social oscilasse abaixo desse patamar, o isolamento social para conter o contágio do novo coronavírus deveria perdurar por 6 meses (cenário 2) ou, até mesmo, 8 meses (cenário 3).

A construção dos "choques" econômicos setoriais do decreto estadual $n^{\circ}$ 47.027/2020 (ERJ, 2020) sobre a demanda final realizada neste estudo não se trata de uma avaliação 
qualitativa dos pesquisadores, como usualmente feito. Os "choques" foram construídos, em sua maioria, levando em consideração as informações de institutos oficiais. Todavia, nem todos os setores produtivos possuem dados atualizados, neste caso, foram utilizadas informações das confederações nacionais e do boletim sobre o comércio varejista brasileiro emitido pela Cielo.

Com base no exposto, o choque da demanda final do setor industrial, comercial e de serviços foi calculado a partir das estatísticas disponibilizadas pelas Contas Nacionais Trimestrais (CNT), Pesquisa Industrial Mensal (PIM-PF/RG), Pesquisa Mensal do Comércio (PMC) e Pesquisa Mensal de Serviços (PMS), todas disponibilizadas pelo IBGE. Já o choque para os demais setores foi calculado com base em informações de outras instituições, tais como: CIELO (2020), CNSEG (2020), IPEA (2020) e UNESCO (2020). A compatibilização dos setores da MIP-RJ com as fontes de dados para a construção dos vetores dos “choques" está sumarizada no Quadro 1.

Quadro 1: Compatibilização dos setores da MIP-RJ com as bases de dados utilizadas para construção dos "choques".

\begin{tabular}{|l|c|c|}
\hline Setores & Base & Fonte \\
\hline Agricultura, pecuária, produção florestal, pesca e aquicultura & Carta de Conjuntura & (IPEA, 2020) \\
& $\mathrm{n}^{\circ} 47$ & \\
Indústrias extrativas & PIM-PF/RG & (IBGE, 2020a) \\
Indústrias de transformação & PIM-PF/RG & (IBGE, 2020a) \\
Eletricidade e gás, água, esgoto, ativ. de gestão de resíduos e descontaminação & CNT & (IBGE, 2020b) \\
Construção & PMC & (IBGE, 2020c) \\
Comério; reparação de veículos automotores e motocicletas & PMC & (IBGE, 2020c) \\
Transporte, armazenagem e correio & PMS & (IBGE, 2020d) \\
Alojamento e alimentação & ICVA & (CIELO, 2020) \\
Informação e comunicação & PMS & (IBGE, 2020d) \\
Atividades financeiras, de seguros e serviços relacionados & Conjuntura CNseg & (CNSEG, 2020) \\
& $\mathrm{n}^{\circ} 20$ & \\
Atividades imobiliárias & CNT & (IBGE, 2020b) \\
Ativ. profissionais, científicas e técnicas, adm. e serviços complementares & PMS & (IBGE, 2020d) \\
Administração pública, defesa e seguridade social & CNT & (IBGE, 2020b) \\
Educação e saúde privadas & Impacto da & (UNESCO, 2020) \\
& COVID-19 na & \\
Artes, cultura, esporte e recreação e outras atividades de serviços & educçãa & (CIELO, 2020) \\
Serviços domésticos & ICVA & PMS \\
\hline
\end{tabular}

Fonte: Elaboração própria.

\section{Resultados}

A crise sanitária do Covid-19 que assolou o mundo e o Brasil trará danos à estrutura produtiva fluminense, aprofundando o processo de desindustrialização e esvaziamento produtivo que o estado do Rio de Janeiro já enfrentava. A economia fluminense vem experimentando uma crise estrutural desde os anos de 1960, o que tem ocasionado o esvaziamento 
produtivo no estado e consequente desarticulação de suas cadeias produtivas. Este processo tornou a estrutura produtiva do estado do Rio de Janeiro frágil e incompleta com poucos encadeamentos produtivos, sendo que apenas os setores da indústria de transformação e extrativa se mostraram como chave para a economia fluminense possuindo capacidade de arrasto sobre a economia (SILVA et al., 2016; CABRAL e OLIVEIRA, 2020).

Entre 2007 e 2017, a participação da economia fluminense no PIB brasileiro caiu de 10,03\% para 8,55\% (IBGE, 2019). No mesmo período, a indústria de transformação e extrativa perderam participação no PIB estadual para os setores de comércio e serviços. A indústria de transformação representava $9 \%$ e a indústria extrativa 16\% do PIB em 2007. Já em 2017, a indústria de transformação passou a representar 5\% e a extrativa apenas 6,7\% do PIB do estado (IBGE, 2019). Mesmo apresentado perda de participação no PIB fluminense, o setor extrativo possui grande relevância econômica para as finanças estaduais e municipais com a geração de receitas de royalties e participações especiais. Apesar disso, os resultados do setor industrial do Rio de Janeiro evidenciam o processo de desindustrialização da economia fluminense.

De 2018 para 2019, a economia fluminense apresentava sinais de recuperação com crescimento de $1,2 \%$ e $1,5 \%$, respectivamente (FIRJAN, 2020). Contudo, esta tímida recuperação será interrompida pelos efeitos decorrentes do novo coronavírus. Atreladas aos efeitos sem precedentes do Covid-19, as graves crises política e econômica do estado do Rio de Janeiro poderão ser agravadas pelo atual momento de instabilidade política vivido no estado, devido ao rompimento dos governos estadual e federal, e a abertura do processo de impedimento do governador.

Com isso, estimar os impactos das medidas de isolamento social na estrutura produtiva torna-se útil para que os policy makers planejem políticas públicas para a retomada do processo de desenvolvimento da economia fluminense. Foram considerados três cenários de medidas de isolamento social mantidos por três, seis ou oito meses, cujos resultados para a economia do estado como um todo e para os macro-setores fluminenses estão reportados na Tabela 1.

Tabela 1 - Impacto total e para os macro-setores setores produtivos da economia do Rio de Janeiro.

\begin{tabular}{llll}
\hline Setores & Cenário 1 & Cenário 2 & Cenário 3 \\
\hline Agropecuária & $-0,60 \%$ & $-0,82 \%$ & $-1,02 \%$ \\
Indústria & $-8,71 \%$ & $-10,13 \%$ & $-11,50 \%$ \\
Comércio e Serviços & $-12,24 \%$ & $-12,93 \%$ & $-13,64 \%$ \\
Total da Economia & $-4,16 \%$ & $-4,59 \%$ & $-5,02 \%$ \\
\hline
\end{tabular}

Fonte: Elaboração própria.

Como é perceptível, a crise sanitária impactará fortemente a economia do estado do Rio de Janeiro com uma queda do PIB variando de 4,16\% a 5,02\%. O setor agropecuário, que representa apenas $0,5 \%$ do valor adicionado no período, deverá apresentar uma queda entre

Econômica-Niterói, v. 22, n. 1, p. 77-93. Junho, 2020 
Tabela 2 - Impactos desagregados para os setores produtivos da economia do Rio de Janeiro.

\begin{tabular}{l|c|c|c}
\hline Setores & Cenário 1 & Cenário 2 & Cenário 3 \\
\hline Agricultura, pecuária, produção florestal, pesca e aquicultura & $-0,61 \%$ & $-0,82 \%$ & $-1,02 \%$ \\
Indústrias extrativas & $2,25 \%$ & $1,68 \%$ & $1,15 \%$ \\
Indústrias de transformação & $-3,47 \%$ & $-3,92 \%$ & $-4,35 \%$ \\
Eletricidade e gás, água, esgoto, ativ. de gestão de resíduos e & $-1,53 \%$ & $-1,75 \%$ & $-1,97 \%$ \\
descontaminação & & & \\
Construção & $-7,49 \%$ & $-7,89 \%$ & $-8,30 \%$ \\
Comércio; reparação de veículos automotores e motocicletas & $-2,21 \%$ & $-2,43 \%$ & $-2,64 \%$ \\
Transporte, armazenagem e correio & $-1,76 \%$ & $-1,99 \%$ & $-2,20 \%$ \\
Alojamento e alimentação & $-34,97 \%$ & $-37,07 \%$ & $-39,29 \%$ \\
Informação e comunicação & $2,70 \%$ & $2,54 \%$ & $2,38 \%$ \\
Atividades financeiras, de seguros e serviços relacionados & $0,31 \%$ & $0,13 \%$ & $-0,03 \%$ \\
Atividades imobiliárias & $-14,11 \%$ & $-14,55 \%$ & $-15,02 \%$ \\
Ativ. profissionais, científicas e técnicas, adm. e serviços complementares & $4,29 \%$ & $4,05 \%$ & $3,82 \%$ \\
Administração pública, defesa e seguridade social & $0,15 \%$ & $0,04 \%$ & $-0,06 \%$ \\
Educação e saúde privadas & $-2,13 \%$ & $-2,29 \%$ & $-2,46 \%$ \\
Artes, cultura, esporte e recreação e outras atividades de serviços & $-46,02 \%$ & $-48,00 \%$ & $-50,06 \%$ \\
Serviços domésticos & $-85,23 \%$ & $-90,42 \%$ & $-95,93 \%$ \\
\hline
\end{tabular}

Fonte: Elaboração própria.

$-0,60 \%$ e $-1,02 \%$. Pelo fato de o setor não ter tradição na economia fluminense, o impacto sobre o agregado da economia será inexpressivo.

No que tange à indústria fluminense, o setor apresentou um crescimento de $9,8 \%$ no primeiro trimestre de 2020 frente a uma retração de 1,37\% da indústria brasileira no mesmo período (IBGE, 2020a). Este bom desempenho no início do ano, liderado pela indústria extrativa, foi fundamental para amenizar o impacto da pandemia sobre o setor industrial fluminense. Considerando os três cenários, estima-se que a retração da indústria do estado do Rio de Janeiro varia entre $8,71 \%$ e $11,50 \%$ para o ano de 2020.

O setor mais impactado será o de comércio e serviços com queda prevista entre 12,24\% a 13,64\%. Como a maioria das atividades destes setores foram consideradas não essenciais pelos decretos estaduais e municipais, comércios e serviços tiveram suas atividades interrompidas durante o período de isolamento social representando um lockdown. Pelo fato de este setor possuir maior participação relativa no PIB fluminense, a forte queda registrada comprometeu consideravelmente as previsões de retração sobre o PIB do estado. Ainda, como este setor responde por, aproximadamente, $70 \%$ dos empregos no Rio de Janeiro (RAIS, 2018), o impacto negativo sobre o setor levará a um expressivo aumento no número de desempregados e informalidade no estado.

Apesar dos resultados pessimistas, é preciso realizar uma análise setorial minuciosa para possibilitar a formulação de políticas públicas setoriais que sejam capazes de minimizar os efeitos decorrentes da pandemia. Os impactos desagregados para a economia do Rio de Janeiro podem ser visualizados na Tabela 2.

Entre os setores mais impactados estão as atividades esportivas e de cultura e entreteni- 
mento (-46,02\% a -50,06\%); os serviços ligados ao turismo como alojamento e alimentação $(-34,97 \%$ a $-39,29 \%)$, e as atividades imobiliárias $(-14,11 \%$ a $-15,02 \%)$. O setor de arte, cultura e esporte tem apresentado instabilidade política desde o início do governo Bolsonaro quando a Cultura deixa de ser ministério e passa a ser uma secretaria. Atrelado a isso, houve redução de $25 \%$ no total de despesas executadas na área de cultura no ano de 2019 em comparação com o ano anterior ${ }^{1}$.

Adicionalmente, as medidas necessárias de isolamento social impactaram diretamente este setor, uma vez que o decreto estadual 47.027/2020 suspendeu a realização de eventos esportivos, shows, feiras científicas, entre outros, em local aberto ou fechado além de proibir o funcionamento de cinemas, teatros, academias, centros de lazer e esportivos e shoppings. Importante lembrar que, mesmo após a abertura da economia, não haverá demanda reprimida por estas atividades, afinal o consumidor não compensará sua demanda não realizada no período de "lockdown" da atividade.

Aliado a isso, é provável que, mesmo com a abertura destas atividades, haja um efeito psicológico sobre o comportamento dos consumidores. Provavelmente, os indivíduos optarão pelo adiamento do consumo destes produtos e serviços até a descoberta da vacina, tendo em vista que o consumo destes bens necessariamente implica em aglomeração.

Sabendo que o Rio de Janeiro é o principal destino de lazer do Brasil e pelo fato de o setor de alojamento e alimentação ser altamente dependente da atividade turística, as medidas de isolamento social impactarão as atividades de alojamento e alimentação de forma similar ao setor de arte e cultura. Ademais, importantes destinos turísticos da Região dos Lagos, Costa Verde e Região Serrana proibiram a circulação de não-residentes enquanto a cidade do Rio de Janeiro, que concentra a maior participação do setor, decretou a proibição de transporte público intermunicipal e interestadual como medidas para conter o avanço do novo coronavirus, reduzindo ainda mais a demanda por tais atividades. Por outro lado, a capacidade do setor se reinventar durante o isolamento social com a expansão dos serviços de delivery e a oferta de hospedagem para profissionais da saúde, além da iniciativa pública de assistência social para hospedagem de idosos em situação de vulnerabilidade em hotéis (Rio de Janeiro e Niterói, por exemplo) amenizaram o impacto da severa restrição imposta pelo decreto estadual 47.027/2020.

Já o setor de atividades imobiliárias é bastante afetado por crises de qualquer natureza, afinal os agentes econômicos adiam consumo desta natureza. Os indivíduos preferem ter em seu portfólio, ativos seguros e com maior liquidez, postergando investimentos imobilizados em tempos de crise. Na China, por exemplo, este setor apresentou queda em torno de $30 \%$ durante as medidas sanitárias (DOW JONES NEWSWIRES, 2020).

A construção civil não ficará isenta dos efeitos negativos decorrentes da pandemia. Este setor já apresentava sucessivas quedas nos anos posteriores à realização dos megaeventos, em decorrência da falta de estímulo à demanda pelo poder público por um lado e pela grande oferta de imóveis disponíveis no mercado por outro lado. Com a pandemia, a perda do

\footnotetext{
${ }^{1}$ Dados disponíveis em: <http://transparencia.gov.br/funcoes/13-cultura?ano=2018>
} 
emprego e renda afetará as decisões de consumo de longo prazo que, somado ao regime de recuperação fiscal das finanças que inviabiliza o investimento estadual, implicará em uma queda entre 7,49\% e 8,30\% para o setor de construção civil em 2020.

Contrapondo estes resultados pessimistas, é possível perceber que alguns setores apresentarão desempenho positivo no ano de 2020, mesmo diante da grave crise política, econômica e sanitária vivida pelo estado do Rio de Janeiro. Destes setores, o que merece destaque é a indústria extrativa devido a sua importância relativa no PIB fluminense e às transferências de royalties e participações especiais para os orçamentos municipais e estadual.

Considerando a excelente produção de óleo e gás $(\mathrm{O} \& \mathrm{G})$ no estado, o setor apresentou crescimento acumulado de $26,81 \%$ no primeiro quadrimestre de 2020 em relação ao mesmo período do ano anterior enquanto a produção brasileira cresceu $16,80 \%$ no mesmo período (IBGE, 2020a). O bom desempenho do setor extrativo fluminense é resultado da excelente produtividade aliado a um baixo lifting cost nos poços do pré-sal. Mesmo com a demanda reduzida, é importante lembrar que o processo de operação de produção offshore não pode parar devido às questões contratuais e operacionais, mantendo a produção relativamente constante durante a pandemia. A título de exemplificação, a produção de $\mathrm{O} \& \mathrm{G}$ no estado no mês de abril, auge da pandemia, ficou atrás apenas da produção do mês de janeiro. Portanto, as estimativas de crescimento de $2,25 \%$ a $1,15 \%$ no ano de 2020 parecem condizentes com a realidade da indústria extrativa fluminense.

Com o processo de flexibilização e reabertura da economia de alguns países, a demanda por petróleo começou a ser retomada. Em abril, as exportações de óleo foram recorde, batendo a marca de 1 milhão de barris por dia, em que 60\% das exportações brasileiras da commodity foram destinadas à economia chinesa. Atrelado a isso, tem-se o aumento dos preços do petróleo após acordo entre Arábia Saudita e Rússia no âmbito da OPEP+. Esta conjunção de fatores na geopolítica do petróleo impulsionará o crescimento do setor no ano de 2020. O resultado positivo para a indústria extrativa foi importante para amenizar o impacto do Covid-19 na economia fluminense, afinal sua participação relativa no PIB é de $8,8 \%$ no período analisado.

\section{Considerações Finais}

Este trabalho teve como objetivo prever os impactos das medidas de isolamento social adotadas pelo estado do Rio de Janeiro sobre a estrutura produtiva fluminense. Para tanto, foi utilizado o método de insumo-produto, considerando três cenários: 1) as medidas de isolamento social terminariam no mês de junho (3 meses); 2) as medidas de isolamento social terminariam no mês de agosto (6 meses); 3 ) as medidas de isolamento social terminariam no mês de outubro (8 meses). Os resultados revelaram que a economia fluminense terá uma retração do PIB variando de 4,16\% a 5,02\% em função da pandemia, agravando ainda mais a crise estrutural vigente.

Desta forma, o Covid-19 provocará expressivos constrangimentos econômicos com sé- 
rias consequências ao tecido socioeconômico do estado do Rio de Janeiro e do Brasil. As previsões para economia brasileira apontam para uma retração em torno de $7 \%$ no ano de 2020. Apesar de possuir uma estrutura produtiva frágil e incompleta, o impacto do Covid-19 sobre a economia do estado do Rio de Janeiro será menor que a média brasileira, visto que, caso as medidas de isolamento se estendam até outubro de 2020, o PIB fluminense reduzirá até $5 \%$.

Diante dos resultados, será preciso planejamento de médio e longo prazo visando o adensamento produtivo por meio de políticas públicas de atração de empresas com o objetivo completar a cadeia produtiva do estado fluminense. No curto prazo, a retomada econômica do estado só será assegurada com estímulos do governo federal para contrabalancear os efeitos da pandemia. Tendo em vista que o estado do Rio de Janeiro está sob o regime de recuperação fiscal, o que impõe serias restrições orçamentarias, medidas como garantia do orçamento dos municípios e do estado, socorro ao setor produtivo, principalmente para as micro, pequenas e médias empresas e renda mínima para as famílias afetadas pela crise sanitária, devem ser garantidas pelo governo federal.

Portanto, é urgente uma política fiscal expansionista do governo federal a todos os entes federados (estados) e subfederados (municípios) brasileiros no curto prazo. Caso contrário, os expressivos efeitos negativos decorrentes da pandemia serão duradouros tanto do ponto de vista econômico quanto social no Rio de Janeiro e no restante do Brasil.

\section{Referências bibliográficas}

BAE, J.-M. A chinese case of coronavirus disease 2019 (covid-19) did not show infectivity during the incubation period: based on an epidemiological survey. Journal of Preventive Medicine and Public Health, Korean Society for Preventive Medicine, v. 53, n. 2, p. 67-69, 2020.

CABRAL, M. V. de F. et al. Análise da estrutura produtiva do setor de turismo do estado do rio de janeiro analysis of productive structure of rio de janeiro state's tourism sector.

CHAN, J. F.-W. et al. A familial cluster of pneumonia associated with the 2019 novel coronavirus indicating person-to-person transmission: a study of a family cluster. The lancet, Elsevier, v. 395, n. 10223, p. 514-523, 2020.

CIELO (Org.). Boletim Cielo varejista exclusivo: impacto do COVID-19 no varejo brasileiro. Cálculo do Índice Cielo do Varejo Amplo (ICVA). Publicado em: maio/2020. Disponível em: <https://www.cielo.com.br/boletim-cielo-varejo/>. Acesso em: 17 de jul. de 2020.

CONFEDERAÇÃO NACIONAL DAS SEGURADORAS - CNseg (Org.). Conjuntura CNseg $n^{o}$ 20: análise de mercado. Publicado em: maio/2020. Disponível em: $<$ http://cnseg.org.br/publicacoes/conjuntura-cnseg-n20.html>. Acesso em: 17 de jul. de 2020.

Econômica-Niterói, v. 22, n. 1, p. 77-93. Junho, 2020 
DIETZENBACHER, E.; LINDEN, J. A. v. d.; STEENGE, A. E. The regional extraction method: Ec input-output comparisons. Economic Systems Research, Taylor \& Francis, v. 5, n. 2, p. 185-206, 1993.

DOMINGUES, E. et al. Cenários de isolamento social da covid19 e impactos econômicos em minas gerais. Nota Técnica Cedeplar, 2020.

DOW JONES NEWSWIRES. China: venda de imóvel cai 34,7\% ao ano no $1^{\circ}$ bimestre, ao ponto mais baixo em 28 anos. Valor Econômico, Pequim, Abril, 2020. Disponível em: <https://valor.globo.com/mundo/noticia/2020/03/16/ china-venda-de-imvel-cai-347-pontos-percentuais-ao-ano-no-1-bimestre-ao-pontol -mais-baixo-em-28-anos.ghtml>.

DUAN, H.; WANG, S.; YANG, C. Coronavirus: limit short-term economic damage. Nature, v. 578, n. 27, 2020.

DWECK, E. et al. Impactos macroeconômicos e setoriais da covid-19 no brasil. Rio de Janeiro, May, 2020.

ESTADO DO RIO DE JANEIRO - ERJ (Org.). Decreto $n^{o} 47.027$ de 13 de abril de 2020. Dispõe sobre as medidas de enfrentamento da propagação decorrente do novo coronavírus (COVID-19), em decorrência da situação de emergência em saúde, e dá outras providências. D.O.E: 13 de abril de 2020. Publicado em: maio/2020. Disponível em: $<$ https://pge.rj.gov.br/comum/code/MostrarArquivo.php?C=MTA2MDQ\%2C >. Acesso em: 29 de jun. de 2020 .

FIRJAN (Org.). Impacto do Corona Vírus sobre a Economia Fluminense. Sondagem industrial. Rio de Janeiro. Abril, 2020. Publicado em: maio/2020. Disponível em: $<$ https://www.firjan.com.br/publicacoes/publicacoes-de-economia/default.htm>. Acesso em: 27 de jun. de 2020.

HADDAD, E. A.; PEROBELLI, F. S.; ARAÚJO, I. F. de. Input-output analysis of COVID-19: methodology for assessing the impacts of lockdown measures. [S.1.]: FEA/USP, 2020.

INSTITUTO BRASILEIRO DE GEOGRAFIA E ESTATÍSTICA - IBGE (Org.). Sistema de contas nacionais. brasil: 2017. rio de janeiro. 2019.

INSTITUTO BRASILEIRO DE GEOGRAFIA E ESTATÍSTICA - IBGE (Org.). Pesquisa industrial mensal - produção física/divulgação regional (pim-pf/rg). rio de janeiro. 2020a.

INSTITUTO BRASILEIRO DE GEOGRAFIA E ESTATÍSTICA - IBGE (Org.). Contas nacionais trimestrais (cnt). rio de janeiro. 2020b.

INSTITUTO BRASILEIRO DE GEOGRAFIA E ESTATÍSTICA - IBGE (Org.). Pesquisa mensal de comércio (pmc). rio de janeiro. 2020c. 
INSTITUTO BRASILEIRO DE GEOGRAFIA E ESTATÍSTICA - IBGE (Org.). Pesquisa mensal de serviços (pms). rio de janeiro. 2020d.

INSTITUTO DE PESQUISA ECONÔMICA APLICADA - IPEA (Org.). Carta de conjuntura $\mathrm{n}^{\circ} 47-2^{\circ}$ trimestre de 2020 . boletim agro: revisão da previsão de crescimento do pib agropecuário brasileiro em 2020 (atualização de abril).

JIANG, S. et al. A distinct name is needed for the new coronavirus. The Lancet, Elsevier, v. 395, n. 10228, p. 949, 2020.

LEONTIEF, W. The structure of American economy, 1919-1929. [S.1.], 1941.

LU, H.; STRATTON, C. W.; TANG, Y.-W. Outbreak of pneumonia of unknown etiology in wuhan, china: The mystery and the miracle. Journal of medical virology, Wiley-Blackwell, v. 92 , n. 4, p. 401, 2020.

MILLER, R. E.; BLAIR, P. D. Input-output analysis: foundations and extensions. [S.1.]: Cambridge university press, 2009.

MINISTÉRIO DA ECONOMIA. Relação anual de informações sociais - rais, brasília. 2018 .

MINISTÉRIO DA SAÚDE (Org.). Covid-19 no Brasil: dados atualizados em 29/06/2020. Disponível em: <https://susanalitico.saude.gov.br/\#/dashboard/>. Acesso em: 29 de jun de 2020.

OMS - Organização Mundial da Saúde (Org.). Novel coronavirus (2019-ncov): situation report, 12. published on february 1, 2020b [cited 2020 apr 1].

OMS - Organização Mundial da Saúde (Org.). Novel coronavirus (2019-ncov): situation report, 22. published on february 11, 2020c [cited 2020 apr 2].

OMS - Organização Mundial da Saúde (Org.). Who director-general's statement on ihr emergency committee on novel coronavirus (2019-ncov). published on january 30, 2020a [cited 2020 apr 1].

ORGANIZAÇÃO DAS NAÇÕES UNIDAS PARA A EDUCAÇÃO, A CIÊNCIA E A CULTURA - UNESCO (Org.). Impacto da COVID-19 na educação. Publicado em maio/2020. Disponível em: <https://pt.unesco.org/covid19/educationresponse>. Acesso em: 17 de jul. de 2020 .

PORSSE, A. A. et al. Impactos econômicos da covid-19 no brasil. Nota Técnica NEDUR-UFPR, v. 1, 2020.

RIBEIRO12, L. C. S. et al. Estimação de impactos econômicos da pandemia covid-19 em sergipe. 2020.

Econômica-Niterói, v. 22, n. 1, p. 77-93. Junho, 2020 
SANTOS, G. F.; RIBEIRO, L. C. S.; CERQUEIRA, R. B. Modelagem de impactos econômicos da pandemia covid-19: aplicação para o estado da bahia12. 2020.

SILVA, T. M. K. da; CABRAL, J. de A.; CABRAL, M. V. de F. Estrutura produtiva da economia do estado do rio de janeiro: Uma análise de insumo-produto. Revista Econômica, v. 18, n. 1, 2016.

SOHRABI, C. et al. World health organization declares global emergency: A review of the 2019 novel coronavirus (covid-19). International journal of surgery, Elsevier, v. 76, p. 71-76, 2020.

Recebido em 11 de agosto de 2020.

Aceito para publicação em 03 de janeiro de 2021. 